\title{
Green Road Construction Using Reclaimed Asphalt Pavement with Warm Mix Additive
}

\author{
Lillian Gungat ${ }^{\#}$, Meor Othman Hamzah ${ }^{*}$ \\ ${ }^{\#}$ Civil Engineering Program, Faculty of Engineering, Universiti Malaysia Sabah, Sabah, Malaysia \\ E-mail: lillian@ums.edu.my \\ *School of Civil Engineering, Universiti Sains Malaysia, Engineering Campus, Pulau Pinang, Malaysia \\ E-mail: cemeor@usm.my
}

\begin{abstract}
Environmental impact and emissions produced from asphalt road construction, promote research on green materials by combining the recycling and warm mix asphalt additive which aims to reduce the environmental impacts. This study evaluates the effects high reclaimed asphalt pavement (RAP) content incorporated with wax warm mix asphalt additive. Milled reclaimed asphalt pavements obtained from local roads were incorporated with a warm mix additive named RH-WMA. These materials were evaluated for the physical and rheological properties, optimum binder content and mechanical properties. It was found that RH-WMA has softening effects on the binder. The additions of 3\% RH-WMA content into 40\% RAP mixture decreased the optimum binder content and energy consumption. Tests on mechanical properties indicated increased on stiffness with the addition of RAP which indicated better resistance to rutting. Additions of RH-WMA on specimens that subjected to combined effects of moisture and aging showed improvement in fatigue resistance. Hence, integration of RAP and RH-WMA showed potential as a green road construction material.
\end{abstract}

Keywords — reclaimed asphalt pavement; warm mix additive; rheological; energy consumption; mechanical properties

\section{INTRODUCTION}

Awareness of environmental impact and emissions reduction has been emphasized globally in recent years. For example, green technology and environmental regulation in asphalt industry have fostered innovations and improvement of old technology in the pavement construction. The asphalt industry is continuously exploring new technology for enhancement of material's performance, improvement of construction efficiency, resources conservation and advance environmental stewardship. The application of reclaimed asphalt pavement (RAP) in road construction and maintenance had gained attention among scientists and asphalt industry due to its cost-effectiveness and environmental benefits. The environmental advantages of the materials recycling include emissions reduction and lower fuel usage related to the extraction and transportation of virgin materials, decreased demand for non-renewable resources and decreased landfill area for disposal of used pavements [1]-[2].

In the United States, the use of reclaimed materials alone conserved about 3.7 million tons of virgin binder which saves approximately USD 2.2 billion [3]. The performance of asphalt mixtures with high RAP content can be improved by modifying the mixture such as using a softer binder grade, incorporating warm mix asphalt (WMA) additive, utilizing rejuvenators, and adding anti-stripping agents. The use of WMA prompted research interest because of its potential benefits to reduce production and compaction temperatures. This study evaluates the use of high reclaimed asphalt content and WMA additive in pavement engineering that can contribute to achieving green road construction.

Used asphalt pavement materials from road maintenance and rehabilitation are usually disposed of. This material can be recycled and incorporated into virgin materials for road maintenance and construction if properly treated. Reclaimed asphalt pavement is the term used to describe the recycling of old pavement in the road construction and rehabilitation, and it consists of valuable aggregate and binder. Typically, asphalt will age over time and becomes stiffer. This process is referred as aging. Several studies have been conducted in the past to evaluate the properties and performance of RAP such as the chemical compound of RAP binder, rheological properties, aging effect, and performance of mixtures containing RAP [4]-[7]. In general, these findings indicate that the use of RAP will increase the stiffness of binder, increased aging index and mixture containing RAP has higher resilient modulus. Aged binder in the RAP will require a higher production temperature which produces more emissions and high energy consumption. Past research 
reported that WMA additive could lower the production temperature due to a reduction in viscosity [8].

Other than lowering the production temperature, WMA additive enables larger quantities of RAP to be used in road construction, improves mixtures workability during construction, reduces odor from HMA plants, less aging of binder and better working environment at construction sites [9]-[11]. The incorporation of RAP increases stiffness and may improve the consistency of mixture performance at high service temperatures. Nevertheless, stiffness should be monitored to avoid fatigue failure [12]. Laboratory and field tests on fatigue resistance of mixture incorporated with RAP and WMA indicated that the addition of WMA additive enhances the fatigue resistance [13]-[14]. In order to promote the use of green materials by recycling the used asphalt and WMA additive locally, it is necessary to evaluate these materials on its rheological and mechanical properties as well as the optimum binder content.

\section{MATERIALS AND METHODS}

\section{A. Materials}

The PG64 binder which equivalent to $80 / 100$ pen and supplied by SHELL Sdn. Bhd was used in this study. This binder is commonly used for local road construction in Malaysia. The granites aggregate was supplied by Kuad Kuari Sdn. Bhd and fulfilled the Jabatan Kerja Raya (JKR) Malaysia aggregate gradation specification for AC14. RAP was obtained by milling process from two local roads along North-South Expressway. North-South Expressway is the main trunk road that links states in Malaysia. In this study, $40 \%$ RAP content based on RAP aggregate was incorporated into virgin materials. A wax WMA additive named RHWMA was incorporated into the RAP and virgin material as a flow improver to decrease the production temperature. A designation shown in Table 1 was adopted to simplify the identification of the mixture blend.

TABLE I

DESIGNATION OF MIXTURE BLEND

\begin{tabular}{|c|c|c|c|}
\hline $\begin{array}{c}\text { Source of } \\
\text { RAP }\end{array}$ & $\begin{array}{c}\text { RAP } \\
\text { Content }(\boldsymbol{\%})\end{array}$ & $\begin{array}{c}\text { Additive } \\
(\boldsymbol{\%})\end{array}$ & Designation \\
\hline 0 & 0 & 0 & PG64 \\
\hline \multirow{2}{*}{ RA1 } & 40 & 0 & RA1 \\
\cline { 2 - 4 } & 40 & 3 & RA1-RH \\
\hline \multirow{2}{*}{ RA2 } & 40 & 0 & RA2 \\
\cline { 2 - 4 } & 40 & 3 & RA2-RH \\
\hline
\end{tabular}

\section{B. Characterization of RAP}

RAP was characterized to ensure its properties are acceptable to be incorporated into the virgin material. The milled RAP was processed in the lab through heating, crushing and sieving. The aggregate gradation of the RAP blends for two different sources of RAP is shown in Table 2.

The binder from the RAP was extracted by using solvent named Trichloroethylene, followed by recovery using rotary evaporator. The physical properties of virgin binder and recovered RAP binders are shown in Table 3.
TABLE II

AGGREGATE GRADATION OF RAP BLENDS

\begin{tabular}{|c|c|c|c|}
\hline \multirow{2}{*}{$\begin{array}{c}\text { Sieve Size } \\
(\mathbf{m m})\end{array}$} & $\begin{array}{c}\text { AC14 } \\
\text { Gradation } \\
\text { Limit }\end{array}$ & \multicolumn{2}{|c|}{ Cumulative Passing (\%) } \\
\cline { 3 - 4 } & 100 & RA1 & RA2 \\
\hline 20 & $90-100$ & 91 & 100 \\
\hline 14 & $76-86$ & 82 & 91 \\
\hline 10 & $50-62$ & 59 & 54 \\
\hline 5 & $40-54$ & 48 & 44 \\
\hline 3.35 & $18-34$ & 26 & 22 \\
\hline 1.18 & $12-24$ & 17 & 14 \\
\hline 0.425 & $6-14$ & 10 & 7 \\
\hline 0.15 & $4-8$ & 6 & 5 \\
\hline 0.075 & & & \\
\hline
\end{tabular}

TABLE III

PROPERTIES OF BINDERS

\begin{tabular}{|c|c|c|c|}
\hline Binders & $\begin{array}{c}\text { Penetration } \\
(\mathbf{d m m})\end{array}$ & $\begin{array}{c}\text { Softening } \\
\text { Points } \\
\left({ }^{\circ}\right)\end{array}$ & $\begin{array}{c}\text { Binder } \\
\text { Content } \\
(\boldsymbol{\%})\end{array}$ \\
\hline PG64 & 82 & 46.5 & - \\
\hline RA1 & 19 & 70.0 & 5.1 \\
\hline RA2 & 9 & 72.0 & 4.9 \\
\hline
\end{tabular}

\section{Specimen Preparation}

The optimum RH-WMA content was determined prior to adding to RAP binder blend. Various percentages of RHWMA $(1,2,3,4$ and 5\%) were added to a binder by the total mass of binder and evaluated for its physical and rheological properties. Rheological properties based on $G^{*} / \operatorname{Sin} \delta$ as stiffness indicator was determined using dynamic shear rheometer (DSR). From the physical and rheological properties tests, an optimum RH-WMA content was selected.

Optimum RH-WMA content was added into RAP during mixture preparation. The addition of RH-WMA into mixture was performed by wet and dry mixing. Wet mixing was applied on the virgin binder. In the wet mixing, RH-WMA was mixed with a virgin binder at $145^{\circ} \mathrm{C}$ for 15 minutes using a mechanical mixer which is based on manufacturer recommendation. Similarly, RH-WMA was added to the batched RAP and then, mixes it manually. For mixing, the virgin aggregate and RAP were heated for 4 and 2 hours, respectively at mixing temperature. At the same time, the virgin binder also was heated to the targeted mixing temperature. After mixing, the loose mixture was short-term aged for 2 hours at the anticipated compaction temperature. All specimens were compacted using the gyratory machine and designed for 100 gyrations to simulate the high traffic. Compaction temperature and optimum binder content were determined by optimization using Response Surface Method (RSM). The input for the optimization also included the conventional marshal mix design parameters such as air voids, voids filled with asphalt, bulk specific gravity, stability and flow [15]. Optimization of RAP-WMA mixtures production based on the method suggested by Derringer was performed to propose the optimum binder content and compaction temperature [16]. Energy consumption was calculated by adopting the method 
proposed by DEFRA and Hamzah et al. as shown in Equation (1) [10], [17].

$$
Q=\sum_{i=n}^{j=n-1} m c \Delta \theta
$$

where $Q$ is the sum of heat energy $(\mathrm{J}), m$ is the mass of material $(\mathrm{kg}), c$ is the specific heat capacity coefficient $\left(\mathrm{J} /\left(\mathrm{kg} /{ }^{\circ} \mathrm{C}\right)\right), \Delta \theta$ is the difference between the ambient and mixing temperature $\left({ }^{\circ} \mathrm{C}\right)$, while $i$ and $j$ indicate different materials types. All specimens were fabricated at $10^{\circ} \mathrm{C}$ higher than the compaction temperature.

\section{Test Procedures}

Specimens were evaluated for mechanical properties such as resilient modulus, indirect tensile strength, and fatigue. The cracking potential of a mixture can be estimated from the tensile failure strain. All test specimens for indirect tensile strength were kept in the incubator at $15^{\circ} \mathrm{C}$ for 4 hours prior to testing. The indirect tensile strength was conducted at $15^{\circ} \mathrm{C}$. Whereas; the resilient modulus test was performed using a Universal Asphalt Testing Machine (UTM-25) at $25^{\circ} \mathrm{C}$. The test was conducted in accordance with ASTM D7369 procedures [18]. The diametral fatigue test simulates the tensile strains developed along the horizontal direction as consequences of repeated loadings by vehicles tires. Besides traffic loading, other factors affecting the fatigue in pavement such as moisture and aging. Hence, specimens for fatigue test were conditioned by simulating the effects of moisture and aging. The specimens were conditioned in distilled water with 6.62 gram/liter concentration of Sodium Carbonate $\left(\mathrm{Na}_{2} \mathrm{CO}_{3}\right)$ to accelerate the stripping in the mixture. After moisture conditioning, specimens were aged in the forced oven for five days to simulate the mixture aging in the field. The moisture and aging procedure were performed in accordance with ASTM D4867 and AASHTO R30 procedures, respectively [19-20]. Diametral fatigue test was conducted based on controlled stress mode in accordance with the procedures in BS 1269724 [21]. Specimens were conditioned at $15^{\circ} \mathrm{C}$ for 4 hours and subjected to three different stress levels.

\section{RESULTS AND DISCUSSIONS}

\section{A. Effects of WMA Additive Content on the Physical and Rheological Properties}

The addition of various RH-WMA content increases the penetration and softening points as presented in Table 4 . The increment in penetration indicates the softening effects of the RH-WMA. On the contrary, the addition of RH-WMA increases the softening point. According to the Federal Highway Administration, some polymer network activated at high temperature when subjected to loading [22]. In the penetration test, the temperature is lower than the testing temperature used for the rutting resistance. Therefore, the polymer component may not activate at this temperature.

The effects of RH-WMA content on $\mathrm{G}^{*} / \mathrm{Sin} \delta$ on the unaged binder is illustrated in Fig. 1. The high-temperature performance grade (PG) of unaged binders is determined based on Superpave specification which is equivalent to 1.0 $\mathrm{kPa}$. It was found that the addition of RH-WMA downgrades the PG by one grade for all RH-WMA content. This indicates that the addition of RH-WMA slightly reduces the binder stiffness. The trend of the $\mathrm{G}^{*} / \mathrm{Sin} \delta$ is divided into two regions. The first region is the concentration of plots for the 1 to $4 \%$ RH-WMA, and the second region is the result of the 5\% RH-WMA. This means that when 5\% RH-WMA added into the binder, it shows more reduction in hightemperature performance grade. By considering the physical properties, the RH-WMA content from 1 to $3 \%$ lies within the local binder specification for $80 / 100$ pen. Meanwhile, the rheological properties of binders with RH-WMA content that more than $4 \%$ show a noticeable reduction of $\mathrm{G}^{*} / \mathrm{Sin} \delta$. Hence, 3\% suggested optimum RH-WMA be incorporated into RAP.

TABLE IV

PHYSICAL PROPERTIES OF BINDERS WITH RH-WMA

\begin{tabular}{|c|c|c|}
\hline $\begin{array}{c}\text { RH-WMA } \\
(\mathbf{\%})\end{array}$ & $\begin{array}{c}\text { Penetration } \\
(\mathbf{d m m})\end{array}$ & $\begin{array}{c}\text { Softening Point } \\
\left({ }^{\mathbf{0}} \mathbf{C}\right)\end{array}$ \\
\hline 1 & 87 & 47.0 \\
\hline 2 & 88 & 47.0 \\
\hline 3 & 89 & 48.0 \\
\hline 4 & 108 & 55.0 \\
\hline 5 & 116 & 60.0 \\
\hline
\end{tabular}

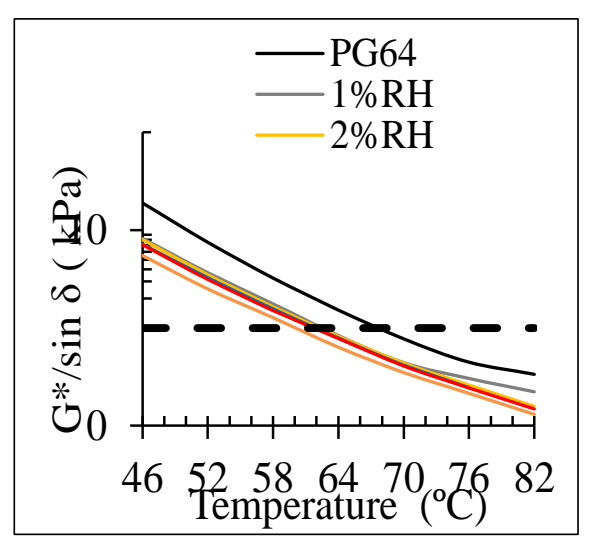

Fig. 1 Effects of RH-WMA content on $\mathrm{G}^{*} / \mathrm{Sin} \delta$

\section{B. Optimum Binder Content}

Optimization using RSM optimizes factors affecting the materials production namely the RAP content, temperature and binder content. Responses are set according to the local asphalt mix design requirement in terms of volumetric and strength properties. Other than the local mix design requirement, optimization also considers the energy consumption. From the optimization, $130^{\circ} \mathrm{C}$ compaction temperature is proposed. Table 5 shows the optimum binder content (OBC) and energy consumption for each mixture. Compaction temperature shows a remarkable increase in energy consumption. Control mixture which was compacted at highest temperature results in highest energy consumption even though the $\mathrm{OBC}$ is the lowest. The addition of RAP increases the $\mathrm{OBC}$ due to aged and stiffer binder. However, the increased of OBC can be counterbalanced by the reuse of valuable binder from the RAP. Noticeable benefits from the addition of RH-WMA can be seen in the reduction of OBC and energy consumption. Energy consumption is one of the determinant factors in green road construction. Reduction of energy consumption implies that there will be less energy and less smoke produced from the asphalt production and 
during paving. Thus, provide a healthy environment to the paving workers.

TABLE V

OPTIMUM BINDER CONTENT

\begin{tabular}{|c|c|c|c|}
\hline Mixture & $\begin{array}{c}\text { Compaction } \\
\text { Temperature } \\
\left({ }^{\circ} \mathbf{C}\right)\end{array}$ & $\begin{array}{c}\text { Optimum } \\
\text { Binder } \\
\text { Content }(\boldsymbol{\%})\end{array}$ & $\begin{array}{c}\text { Energy } \\
\text { Consumption } \\
(\text { Tera Joule) }\end{array}$ \\
\hline PG64 & 150 & 5.2 & 3.255 \\
\hline RA1 & 130 & 5.7 & 2.857 \\
\hline RA1-RH & 130 & 5.5 & 2.854 \\
\hline RA2 & 130 & 5.8 & 2.967 \\
\hline RA2-RH & 130 & 5.6 & 2.960 \\
\hline
\end{tabular}

\section{Mechanical Properties}

Mechanical properties of mixture evaluated based on indirect tensile strength (ITS), resilient modulus $\left(\mathrm{M}_{\mathrm{R}}\right)$ and fatigue test. Fig. 2 shows the ITS result of various mixture types. The addition of RAP produces a stiffer mixture and hence increases the ITS. Goh and You reported similar finding on the increased ITS with the addition of RAP but on the porous asphalt [23]. The stiffness of RAP is affected by the source of RAP whereby RA2 indicates higher ITS compares to RA1. Penetration and stiffness based on performance grade indicate that the RA2 binder is stiffer compared to RA1. Stiffness in RAP is related to aging due to oxidation.

According to $\mathrm{Lu}$ and Isacson, aging attributed to the characteristics of the binder, nature of aggregates and particle size distribution, air voids of the mixture, production-related factors, temperature and time [24]. Modification of RAP mixtures with RH-WMA slightly reduces the ITS for RA1-RH and RA2-RH about 2.69 and $0.54 \%$.

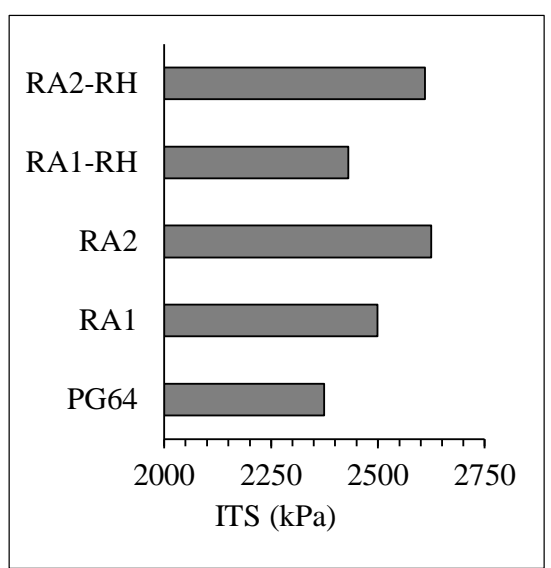

Fig. 2 ITS of RAP with RH-WMA

Resilient modulus result is presented in Fig. 3. As shown, the resultant graphs exhibit similar trends with the ITS results whereby the resilient modulus increases with the addition of RAP. This finding is in agreement with the study conducted by Arshad et al. on the RAP-WMA mixtures containing 30, 40 and 50\% with Sasobit [25]. The addition of RAP produces a stiffer mixture due to aged binder and aggregate. Mixture with high stiffness will have better resistance to rutting which commonly occurred in a tropic region such as Malaysia.

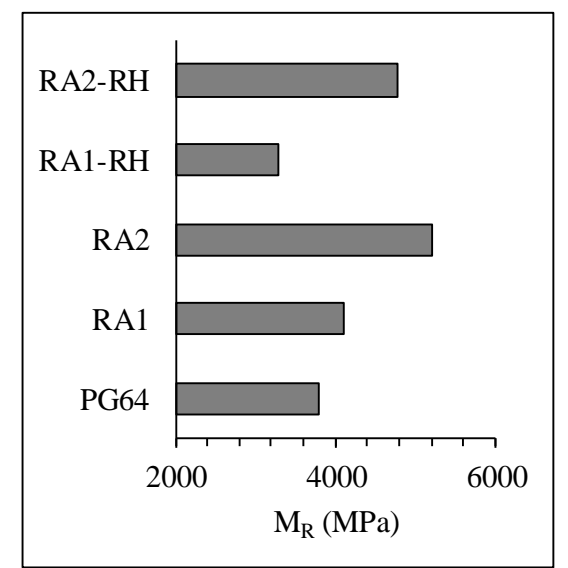

Fig. 3 Resilient modulus of RAP with RH-WMA

Initial strain and maximum tensile at the center of the specimen are calculated before the determination of fatigue failure. In this study, the initial stiffness is equivalent to the value at $100^{\text {th }}$ loading cycle which is in accordance with the European Standard EN 12697-24 procedure [26]. Determination of fatigue failure is based on the number of cycles until the specimen failed.

Fatigue failure can be indicated by the gradient of the graph or $n$ based on the power equation. Higher gradient shows better fatigue resistance. Comparison of mixtures resistance to fatigue is presented in Table 6. In general, the addition of RAP exhibits lower $n$ and indicates a reduction in the mixture resistance to fatigue. The addition of RH-WMA shows improvement of fatigue resistance in RA1-RH. By comparing the regression coefficient $n$ of PG64 or control with the RA1-RH, the difference is about $31 \%$. This means that even though the RAP mixture stiffens and compacted at slightly lower temperature, its' resistance to fatigue is comparable to the control with the addition of RH-WMA.

TABLE VI

FATIGUe CURVE REgRESSION PARAMETERS

\begin{tabular}{|c|c|c|c|}
\hline \multirow{2}{*}{ Mixture } & \multicolumn{2}{|c|}{ Regression Coefficient } & \multirow{2}{*}{$\mathbf{R}^{\mathbf{2}}$} \\
\cline { 2 - 3 } & $\mathbf{K}$ & $\boldsymbol{n}$ & \\
\hline PG64 & $5.00 \mathrm{E}+08$ & -2.005 & 0.9468 \\
\hline RA1 & $2.00 \mathrm{E}+07$ & -1.337 & 0.9856 \\
\hline RA1-RH & $7.00 \mathrm{E}+07$ & -1.376 & 0.8777 \\
\hline RA2 & $2.00 \mathrm{E}+06$ & -0.789 & 0.9149 \\
\hline RA2-RH & $6.00 \mathrm{E}+06$ & -0.934 & 0.9851 \\
\hline
\end{tabular}

According to McDaniel and Anderson, the stiffness of the mixture can dramatically increase with the inclusion of RAP [27]. When using high RAP content, the fatigue resistance can be reduced due to the addition of aged binder that stiffened the mixtures [28]. Nevertheless, the addition of RH-WMA improves the fatigue resistance in comparison with a mixture containing RAP only. Similar findings on the fatigue life improvement with the used of WMA additive by using other test methods were also reported in previous research [13], [18]. In terms of moisture and aging effects on the fatigue resistance, Tong et al. stated that moisture and aging are two main components that can significantly increase the potential for fatigue cracking to develop in a mixture [29]. Aging stiffens the binder and hence accelerates 
the cracking development. On the contrary, moisture weakens the bonding between the aggregate and binder.

\section{CONCLUSIONS}

Based on the test results, a few conclusions are drawn. The additions of various RH-WMA contents into RAP binder blend exhibited a softening effect. Based on the physical and rheological tests results as well as the local specification, the optimum RH-WMA content was 3\%. Therefore, 3\% RH-WMA was incorporated into RAP mixture. Optimum binder content determined from the optimization using RSM indicated that compaction temperature showed the noticeable effect on the energy consumption and addition of RH-WMA reduced the OBC and energy consumption. With the addition of RH-WMA, the mixture can be compacted at $130^{\circ} \mathrm{C}$ which is lower than the conventional mixture. As a consequent, greener environment during road construction is expected. In terms of mechanical properties, resilient modulus and ITS increased with the addition of RAP hence produced stiffer mixtures. Mixture with high stiffness exhibited a lower fatigue resistance. However, the addition of RH-WMA into the mixture showed potential in improving the fatigue resistance. Specimen RA1-RH showed comparable fatigue resistance with mixture without RAP even though subjected to the combined effects of moisture and aging. Past research reported that moisture and aging significantly increases the potential of fatigue failure in mixture with RAP. In summary, the integration of RAP and WMA additive such as RH-WMA indicated the material's potential for a greener road construction with better mechanical properties.

\section{ACKNOWLEDGMENT}

This work was supported by the Universiti Sains Malaysia under the Research University Individual Grant Scheme (RUI Grant Number 1001/PAWAM/814231).

\section{REFERENCES}

[1] R. West, Reclaimed Asphalt Pavement Management: Best Practices. Auburn, AL: National Center for Asphalt Technology, NCAT Draft Report, 2010.

[2] M.I Ali, S. Abdullah and T.I. Mohamad, (2011) "Performance of Untreated Waste Cooking Oil Blends in a Diesel Engine", International Journal on Advanced Science, Engineering and Information Technology, 1(5), 523-527, 2011.

[3] NAPA, FHWA Seek Input from Asphalt Mix Producers for Survey, Online Report. 2013.

[4] J. Daniel, and A. Lachance, "Mechanistic and Volumetric Properties of Asphalt Mixtures with Recycled Asphalt Pavement", Transportation Research Record: Journal of the Transportation Research Board, 1929(-1), 28-26, 2005.

[5] R. S. McDaniel, A. Shah, G.A. Huber and V.L. Gallivan, "Investigation of Properties of Plant-Produced RAP Mixtures," Transportation Research Record: Journal of the Transportation Research Board, No. 1998, Transportation Research Board, 103-111, 2007

[6] X. Shu, B. Huang and D. Vukosavljevic, "Laboratory Evaluation of Fatigue Characteristics of Recycled Asphalt Mixture", Construction and Building Materials, 22(7), 1323-1330, 2008

[7] A. Jamshidi, M. O Hamzah, Z. Shahadan and A. S. Yahaya, "Evaluation of the Rheological Properties and Activation Energy of Virgin and Recovered Asphalt Binder Blends", Journal of Materials in Civil Engineering, 27(3), 1-11, 2014.
[8] M.C. Rubio, G. Martínez, L. Baena, L. and F. Moreno, "Warm Mix Asphalt: An Overview", Journal of Cleaner Production, 24, 76-84, 2012.

[9] A. Copeland, J. D'Angelo, R. Dongré, S. Belagutti, S. and G. Sholar, "Field Evaluation of High Reclaimed Asphalt Pavement-Warm-Mix Asphalt Project in Florida: Case Study", Transportation Research Record: Journal of the Transportation Research Board, (2179), 93$101,2010$.

[10] M.O. Hamzah, A. Jamshidi, A. and Z. Shahadan, "Evaluation of the Potential of Sasobit ${ }^{\circledR}$ To Reduce Required Heat Energy and CO2 Emission in the Asphalt Industry", Journal of Cleaner Production, 18(18), 1859-1865, 2010.

[11] A. Banerjee, A. De Fortier Smit and J.A. Prozzi, "The Effect of Long-Term Aging on the Rheology of Warm Mix Asphalt Binders", Fuel, 97, 603-611, 2012.

[12] M. Zaumanis and R.B. Mallick, "Review of Very High-Content Reclaimed Asphalt Use In Plant-Produced Pavements: State of The Art", International Journal of Pavement Engineering, 16(1), 39-55, 2015.

[13] D.H. Timm, J.R Willis A and Kvasnak, "Full-Scale Structural Evaluation of Fatigue Characteristics in High Reclaimed Asphal Pavement and Warm-Mix Asphalt", Journal of the Transportation Research Board, 2208, 56-63, 2011.

[14] S. Zhao, B. Huang, X. Shu, X. Jia and M. Woods, "Laboratory Performance Evaluation of Warm-Mix Asphalt Containing High Percentages of Reclaimed Asphalt Pavement", Transportation Research Record: Journal of the Transportation Research Board, 2294(1), 98-105, 2012.

[15] A. Setiawan, L.B. Suparma, and A.T. Mulyono, "Modelling Effect of Aggregate Gradation and Bitumen Content on Marshall Properties of Asphalt Concrete", International Journal on Advanced Science, Engineering and Information Technology, 7(2), 359-365, 2017.

[16] G. Derringer, "Simultaneous Optimization of Several Response Variables', Journal of Quality Technology, 12, 214-219, 1980.

[17] DEFRA, Guidelines to GHGs Calculations. Department for Environment, Food and Rural Affairs, United Kingdom, 2010.

[18] ASTM, ASTM D7369 Standard Test Method for Determining the Resilient Modulus of Bituminous Mixtures by Indirect Tension Test, American Society for Testing and Materials, Conshohocken, PA, United States, 2011.

[19] ASTM, ASTM D 4867/D 4867M, Standard Test Method for Effect of Moisture on Asphalt Concrete Paving Mixtures, American Society for Testing and Materials Conshohocken, PA, United States, 2004.

[20] ASTM, ASTM D6521, Standard Practice for Accelerated Aging of Asphalt Binder Using a Pressurized Aging Vessel (PAV), American Society for Testing and Materials. Conshohocken, PA, United States, 2006.

[21] British Standard, BS EN 12697-24, Bituminous Mixtures, Test Methods for Hot Mix Asphalt. Resistance to Fatigue, 2012.

[22] Federal Highway Administration (FHWA), The Multiple Stress Creep and Recovery (MSCR) Procedure, FHWA HIF-11-0.38, 2012.

[23] S. Goh and Z. You, "Mechanical Properties of Porous Asphalt Pavement Materials with Warm Mix Asphalt and RAP", Journal of Transportation Engineering, 138(1), 90-97, 2012.

[24] X. Lu and U. Isacsson, "Rheological Characterization of StyreneButadiene-Styrene Copolymer Modified Bitumens", Construction and Building Materials, 11(1), 23-32, 1997.

[25] A. K. Arshad, F. A. M. Kridan, N. A. Kamaluddin and E. Shafie, "Evaluation of Warm Mix Asphalt Performance with High RAP Content", Jurnal Teknologi, 73(4), 51-54, 2015.

[26] European Standard EN 12697-24. Bituminous Mixtures. Test Methods for Hot Mix Asphalt. Resistance to Fatigue, 2004

[27] R. S. McDaniel and R. M. Anderson, Recommended Use of Reclaimed Asphalt Pavement in The Superpave Mix Design Method. Technician's Manual, NCHRP Report 452. Transportation Research Board Washington, D.C, 2000.

[28] M. Sabouri, T. Bennert, J. Sias Daniel and Y. Richard Kim, "A Comprehensive Evaluation of the Fatigue Behaviour of PlantProduced RAP Mixtures", Road Materials and Pavement Design, 126, 2015.

[29] Y. Tong, R. Luo and R. L. Lytton, "Moisture and Aging Damage Evaluation of Asphalt Mixtures Using the Repeated Direct Tensional Test Method", International Journal of Pavement Engineering, 16(5), 397-410, 2015. 